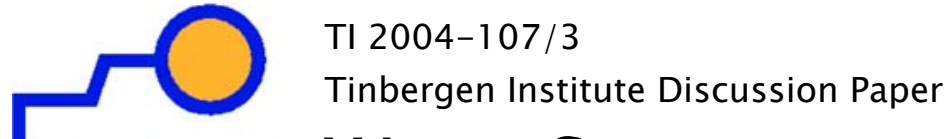 Wage Structure and the Incentive Effect of Promotions
}

\author{
Marco van Herpen \\ Kees Cools \\ Mirjam van Praag ${ }^{2}$
}

' Groningen University, and $B C G$,

2 SCHOLAR, University of Amsterdam, and Tinbergen Institute. 
Tinbergen Institute

The Tinbergen Institute is the institute for economic research of the Erasmus Universiteit Rotterdam, Universiteit van Amsterdam, and Vrije Universiteit Amsterdam.

Tinbergen Institute Amsterdam

Roetersstraat 31

1018 WB Amsterdam

The Netherlands

Tel.: $\quad+31(0) 205513500$

Fax: $\quad+31(0) 205513555$

Tinbergen Institute Rotterdam

Burg. Oudlaan 50

3062 PA Amsterdam

The Netherlands

Tel.: $\quad+31(0) 104088900$

Fax: $\quad+31(0) 104089031$

Please send questions and/or remarks of nonscientific nature to driessen@tinbergen.nl.

Most TI discussion papers can be downloaded at http://www.tinbergen.nl. 


\title{
Wage Structure and the Incentive Effect of Promotions*
}

\author{
MARCO VAN HERPEN ${ }^{1}$ \\ University of Groningen \& \\ The Boston Consulting Group \\ KEES COOLS \\ University of Groningen \& \\ The Boston Consulting Group \\ MIRJAM VAN PRAAG \\ Faculty of Economics and Econometrics \\ University of Amsterdam \\ SCHOLAR Program \\ Tinbergen Institute
}

May 2004

\begin{abstract}
This paper studies wage structure characteristics and their consequent incentive effects empirically. Based on personnel records and an employee survey, we provide evidence that wages are attached to jobs and that promotions play a dominant role as a wage determinant. Our findings indicate furthermore that a promotion affects both intrinsic and extrinsic motivation significantly, though in two different ways: an expected promotion increases extrinsic motivation whereas intrinsic motivation is highest subsequent to a realized promotion. The relationship between extrinsic motivation and expected promotions implies that promotions have a clear incentive effect, consistent with a key - not yet tested assumption of the tournament model.
\end{abstract}

Keywords: promotions, incentives, tournament model, internal labor market, extrinsic motivation, intrinsic motivation

JEL Codes: J41 J33

\footnotetext{
* Special thanks to George Baker, Ben Kriechel, seminar participants at Aarhus Business School and the EALE conference 2003 for helpful comments and discussions.

${ }^{1}$ Contact details: Marco van Herpen, J.F. Kennedylaan 100, 3741 EH Baarn, The Netherlands, tel.: +31-(0)35 5486956, e-mail: vanherpen.marco@bcg.com
} 


\section{Introduction}

Are wages attached to jobs and do promotions play an important role as a wage determinant? Do expected promotions affect motivation and, once the promotion has been realized, will this make the motivation disappear completely? We empirically address these questions, which are all related to tournament theory, one of the seminal contributions to personnel economics (cf Lazear and Rosen, 1981).

Although empirical research into personnel economics has its origins in 1980 (Medoff and Abraham, 1980), empirical personnel economics has only recently left its infancy (e.g. Lazear (1992, 1999), Baker, Gibbs and Holmstrom (1994a, 1994b), Lazear (2000), Treble, van Gameren, Bridges and Barmby (2001) and Dohmen, Kriechel and Pfann (2003)). These empirical studies indicate regularities regarding promotions, wages, and performance evaluations but are unable to answer the questions mentioned above unequivocally. In particular, the tournament model has been subject to little empirical research as of yet. ${ }^{2}$

Following the example of Baker, Gibbs and Holmstrom (hereinafter BGH, 1994a and 1994b), our data are collected at a single research site, having the benefit of homogeneous company culture and the lack of other unobserved heterogeneity of company characteristics. Using the corporate labor agreements and the personnel files of a listed Anglo-Dutch company, we determine the effect of individual promotions on wages relative to the effect of incentive compensation on wages. We find that the wage-pattern is convex and that promotions are the most dominant factor in establishing this wage pattern. The direct effect of a promotion on fixed wages is $5 \%$. Further analyses show that promotions increase the automatic average wage growth of $3.5 \%$ p.a. by an additional average $25 \%$ to $4.4 \%$. These

\footnotetext{
${ }^{2}$ Exceptions are, among others: Knoeber and Thurman (1994), Eriksson (1999) and Coupé, Smeets and Warzynski (2004).
} 
results are consistent with $\mathrm{BGH}(1994 \mathrm{a}, 1994 \mathrm{~b})$ as well as with the tournament model. The effect of incentive compensation on wages is limited.

The main contribution of this study is the novel empirical analysis of the relationship between promotions and motivation. Based on a survey amongst all individual employees, we find a positive significant effect of promotions on both intrinsic and extrinsic motivation, which indicates the effectiveness of promotions. We show that promotions affect extrinsic motivation positively consistent with one of the basic assumptions in the tournament model. This type of motivation is high if an employee expects to be promoted in the near future. Intrinsic motivation is not so much affected by an expected promotion but rather by a recently realized promotion. Long periods without a realized or expected promotion lead to a decrease in intrinsic motivation.

The paper proceeds as follows. First, we discuss the theoretical background with a special focus on the tournament model and motivational aspects. Section three continues with the discussion of the research site, which is followed by the results. The last section concludes.

\section{Theoretical Background}

The internal economics of firms have challenged many theorists to develop models of wage growth. Gibbons (1997) distinguishes four main models that explain career ladders and wage structures, namely task-assignment, learning, human-capital theory and the tournament model. This paper focuses on the tournament model. In order to be able to distinguish the tournament model from other models that can derive similar empirical outcomes, we will first briefly discuss the relevant features of these other three models. Subsequently we will continue with (an empirical view of) the tournament model and explain the unique properties of this model. 


\subsection{Theoretical models on job ladders}

Task-assignment models are intended to explain the distribution of wages as an outcome to the problem of assigning jobs to employees (Sattinger, 1993). In some models especially the signaling effect of a promotion is important (e.g. Bernhardt en Scoones, 1993). A promotion signals the ability of the employee to other firms. Therefore, the assignment models can lead to two specific outcomes relevant for our study. First, the signaling effect of a promotion will make potential employers bid up the wage of the promoted employee (i.e. wage increase upon promotion). Furthermore, the promotion criteria can become inefficient in the sense that employees that would perform marginally better in a higher job are not promoted due to the imposed wage-increase (Gibbons, 1997).

Learning (or job matching) models also concentrate on information problems (i.e. imperfect information). In these models, the ability of a certain employee is unknown, exante, but becomes clearer over time as tenure increases (Jovanovic, 1979). Since job matching models originated as job mobility models, the disclosure of information on the quality of a match will lead to either a wage increase (when the match is good) or turnover to a better matched firm. Both task-assignment models and learning models use the properties of imperfect information and can derive convex wage structures as a solution.

The third type of models is based on Human-Capital Theory. This theory has been shaped by works by Becker, Mincer and Schultz (in: Gibbons and Waldman, 1999b). Already with Becker's (1962) influential article the concept of general versus firm-specific human capital was introduced. General human capital refers to human capital that is equally valued by all firms. On the other hand, firm-specific human capital refers to knowledge that is useful only in the organization where the employee currently works. Carmichael (1983) links human-capital theories to the career tracks within organizations. He concludes that wages 
attached to jobs and jobs assigned by seniority can derive an efficient outcome of careers and wage structure.

These three models start from the perspective of innate and developed ability. Building on these models, Gibbons and Waldman (1999a) have developed an integrated model, which is a combination of the human-capital theory (in specific, general human capital), job assignment, and learning (regarding the abilities of the employees). Gibbons and Waldman (1999a) distinguish two types of innate ability, namely a high and a low level. Their model concludes that expected ability is completely transferred into wages for the employees. Other conclusions of the Gibbons and Waldman model (and its extensions) relevant to our study are that promotions imply a wage increase, demotions, although rare, imply a wage decrease, wages are serially correlated in time, and wage increases predict promotions (Lima and Pereira, 2003).

\subsection{Tournament model}

While all three models discussed use the ability of employees as a starting point, this is not the only determinant of performance. Lawler (1986) distinguishes between ability and effort, where effort refers to the extent employees are willing to exert themselves.

The seminal model that explicitly focuses on the incentive effect of a wage structure (and not on differentiations within or uncertainty about the level of ability) is the tournament model (Lazear and Rosen, 1981). The main characteristic of the tournament model is that no formal contracts exist; all contestants are ranked based on their performance. The winner(s) will go on to the next round. The tournament model shows that promotions are a substitute for incentive compensation. A key distinction between both types of motivational instruments concerns the way performance is or can be measured. A promotion is awarded based on relative performance, not absolute performance. The latter is typically, though not necessarily, used as a basis for performance pay. 
Three features of the tournament theory are essential. First, the wage slots are fixed in advance. Second, a promotion is not awarded to a worker because he is good, but because he is better than the other contestants. Third, the level of effort depends on the size of the salary increase caused by the promotion. Thus, not the absolute level of the high wage level is important, but the wage increase after promotion (Lazear, 1995).

Rosen (1986) extends the basic model, consisting of one round (Lazear and Rosen, 1981), with multiple rounds in which employees are eliminated from further participation in the tournament after losing a round. With multiple rounds, the expected (option) value of further wage increases for participating in subsequent rounds decreases and is zero in the final round. The decreasing option value of wage increases in further rounds at increasing hierarchical levels has to be compensated by disproportional increases of the guaranteed wage for the winner in the last rounds of the tournament or, in other words, a convex wagestructure.

Empirical evidence on the tournament model is scarce, although some of the main characteristics are testable. Most empirical articles provide evidence on the tournament model using sporting events (e.g. Ehrenberg and Bognanno, 1990a \& 1990b; Taylor and Trogdon, 2002). Apart from experimental evidence, examples of the rare articles that empirically analyze the tournament model within firms are O’Reilly, Main and Crystal (1988), Main, O’Reilly and Wade (1993), Knoeber and Thurman (1994), Eriksson (1999) Bingley and Eriksson (2001) and Coupé, Smeets and Warzynski (2004). In general, these studies find support for the tournament theory.

Testable implications of the tournament model are the existence of fixed wage-slots and of a convex wage-structure. Although these characteristics are necessary conditions, they are not unique for the tournament model. Task-assignment models, learning models or the human-capital theory can potentially derive similar results. A testable assumption of the tournament model is that promotions based on relative performance evaluation provide 
incentives. Lazear (1995) writes about this incentive effect of tournaments based on relative performance evaluation: "... many, including myself, believe that most motivation is produced not by an absolute reward, but by compensation that is based on relative comparisons." Consequently, besides empirically analyzing direct implications concerning wage structure, the relevance and working of the tournament model can also be studied by analyzing one of the basic assumptions, namely the motivating and incentive effect of promotions in corporate practice.

\subsection{Intrinsic and Extrinsic Motivation}

The distinctive assumption of the tournament model is the use of incentives to elicit effort as a starting point, rather than human capital and ability. In general, economists while talking about incentives and motivation, refer to one type of motivation: extrinsic motivation (Frey, 1997b, Bénabou and Tirole, 2003). Extrinsic motivation is a type of behavior induced by external interventions, such as monetary rewards, praise by your boss, or status (Frey, 1997a). This type of incentives works like quid pro quo: employees have the (implicit) contract that after delivering a certain performance they will receive an external reward. In our study this means that the prospect of monetary rewards, either in the form of incentive compensation or promotions, will increase extrinsic motivation.

Recently, economists have also become interested in the incongruent component of extrinsic motivation: intrinsic motivation (e.g. Frey, 1997b; Kreps, 1997; Kunz and Pfaff, 2002; Bénabou and Tirole, 2003). Intrinsic motivation is defined as the individual's desire to perform a task for it's own sake (Bénabou and Tirole, 2003). Originating from a sociological and psychological background, the distinction between intrinsic and extrinsic motivation was introduced in economics through the crowding theory of Frey (Frey, 1997a and Frey, 1997b). This theory focuses upon the "hidden costs" of rewards and punishments. In brief, crowding theory describes when an outside interference such as incentive compensation, that ought to 
lead to increased extrinsic motivation, is expected to "crowd out" or "crowd in" intrinsic motivation. Bénabou and Tirole (2003) have formalized the distinction between intrinsic and extrinsic motivation and indicated the importance of both while trying to identify the overall effect of external interventions on motivation.

In our study we wish to make use of the distinctive effects of promotions on intrinsic and extrinsic motivation, thus expanding the tournament model. Investigations into the previously mentioned hidden costs of rewards have both theoretically and empirically mainly been limited to monetary compensation. However, promotions are also expected to affect intrinsic motivation, as opposed to extrinsic motivation. As Bénabou and Tirole (2003) note, "discretionary" or "ex post" rewards, such as promotions, can increase the self-esteem and intrinsic motivation of an individual. A promotion can also be a signal of trust and lead to empowerment, which in turn is associated positively with intrinsic motivation (Deci and Ryan, 1985). The potential relationship ${ }^{3}$ between perceived promotion opportunities and intrinsic motivation will be included in our analyses in order to determine the full incentive effect of promotions.

\section{Case Study}

The research site is the Dutch headquarters of an Anglo-Dutch publicly listed company. Because of a recent merger the wage policy had to be adjusted in order to align procedures. Three sources of data were used. First of all, the collective labor agreement and other regulations were studied in detail to understand the wage structure, as the company explicitly designed it. Secondly, annual employee data were collected in 2002 stretching back to 1998 , just after the merger. The third source of data consists of survey results. All employees for

${ }^{3}$ Van Herpen, van Praag, and Cools (2002) found support for a relationship between perceptions regarding promotions and intrinsic motivation. 
whom employee data are available were sent a questionnaire by e-mail, which was designed after extensively interviewing employees and managers throughout the company. The filledout questionnaires were matched with the employee data. ${ }^{4}$ In this section the merged databases will be analyzed in three steps. We first discuss the internal rules and regulations, then we analyze the personnel data, and finally we examine the combined set of personnel and survey data.

\subsection{Internal rules and regulations}

In this subsection the Collective Labor Agreement (CLA) is discussed. The CLA is a temporary contract, which specifies general rules for salary, increases (and decreases), benefits, bonuses, promotions or demotions, evaluation scores, vacations, etc. A Dutch CLA is negotiated between the management of a company or a representative group of employers within an industry on the one side and the trade unions on the other. It is common to strictly enforce the CLA, including with non-union employees. Consequently, the regulations in the CLA strongly determine the salary structure. The results show that this company does not deviate from earlier findings, meaning that U.S. based companies (e.g. BGH, 1994a, 1994b) show patterns of wage-structures that are similar to the one in this particular CLA. Two distinct components form the basis of the remuneration system in this CLA: the so-called broadband system and the merit matrix.

\section{Broadbands}

The salary structure of this company is the result of a job weighing system in which each job is rated based on certain criteria. Jobs are classified, based on these ratings, in one of seven salary scales, called broadbands. Each broadband is divided into four quartiles and has a

\footnotetext{
${ }^{4}$ Discrete and anonymous handling of the questionnaires was guaranteed by the management, the workers council and the researchers in order to avoid the risk of social desirable answers. Overall response rate was $28 \%$.
} 
specified minimum and maximum salary, see Figure 1. The strict application of this salary system confirms the observation that wages are primarily attached to jobs and not to individuals (Doeringer and Piore, 1971 and BGH, 1994a).

\section{$<<$ INSERT FIGURE 1 HERE $>>$}

As one can see, the relationships between the maximums of the broadbands show a convex figure; the same holds for the minimums. This is illustrated in Table 1, which also shows two additional regularities. The first is that the scale maximum (and minimum) does not increase with a constant multiplier, but that the multiplier itself is enlarged over the broadbands. The difference between the maximum of broadbands 1 and 2 is $14.4 \%$, while the same difference between broadband 6 and 7 is $28.9 \%$. The broadbands are therefore also slightly convex in the logarithm of the wages. The second regularity is the different multipliers that are being used for the minimum and maximum of the broadbands. In the changes between broadbands $1=>2,2=>3$ and $3 \Rightarrow>4$ the increase in terms of percentage is higher for the minimum of the broadbands than for the maximum of the broadbands. The result is that the relative spread between the maximum and the minimum of these broadbands decreases.

$<<$ INSERT TABLE 1 HERE $>>$

\section{Merit Matrix}

To determine the annual salary increase of each individual employee a merit matrix is incorporated in the CLA. The merit matrix uses two input variables. The first variable is the 
quartile in which the employee is ranked within the broadband..$^{5}$ The second variable is the evaluation score of the employees. Each employee receives an annual evaluation score on a 5point scale, based on their performance benchmarked against targets that vary over jobs. "A" is the most positive evaluation score ("Consistently exceeds the requirements of the job, excellent performance"), "C" the norm ("Normal performance, meets all requirements of the job") and "E" the most negative score ("Below standard"). The actual salary increase is the factor determined by the merit matrix, multiplied by a percentage $(\mathrm{N})$. The $\mathrm{N}$ factor is usually the outcome of negotiations between the unions and the management. The maximums and minimums of the broadbands are each year raised with $\mathrm{N}$ as well. The complete matrix is displayed in Table 2.

$<<$ INSERT TABLE 2 HERE $>>$

The table shows that lower quartiles have a higher multiplier factor than the higher quartiles. For example, in the first quartile the employees receive 1.5 times $\mathrm{N}$ while they will receive $\mathrm{N}$ for the same evaluation score in the fourth quartile. There are two possible explanations for this. The first explanation draws on the human-capital theory. One can expect young, newly hired employees to start in the first quartile of a broadband. Learning on the job will make them invest in their abilities, which can build firm-specific human capital. In order to compensate for these investments and reward the learning curve, employees in the lower quartiles will receive a higher reward. Compensation based on tenure in the broadband, which will be an outcome of the used matrix, is an indication that wages are not solely attached to the job function but also to the individual employees. The second explanation for the merit matrix used is based on the equity theory (e.g. Locke and Henne, 1986). This theory explains

\footnotetext{
${ }^{5}$ The merit matrix also uses a so-called "fifth quartile", intended for employees that for some historic reasons have a salary that exceeds the scale maximum.
} 
that employees prefer to receive fair compensation compared to their peers (other employees).

Using this point of view, a convergence to the same salary level for employees in the same position, excluding their performance, is desired. ${ }^{6}$

The significance of evaluation scores for salary increases is illustrated by studying the differences in impact of an A assessment score and a D-score, both relative to a C-score. Looking at the first quartile, we see that receiving an A-score will give an extra salary increase of $0.5 * \mathrm{~N}$ compared to the C-score. A D-score will reduce the salary increase by 0.7 * $\mathrm{N}$. This implies that a D evaluation score in one year cannot be fully compensated by an Ascore in the next year. This is even stronger in the fourth quartile: An A-score increases the compensation with $0.35 * \mathrm{~N}$ extra, while a D-score decreases the compensation with $0.80 * \mathrm{~N}$. The conclusion is that although a positive assessment has a positive effect on salary increases, the negative effect of a low evaluation score is much larger. The company seems to use a stick, rather than a carrot to motivate employees. ${ }^{7}$

Not incorporated in the merit matrix, but included in the CLA is the salary increase resulting from a promotion from a lower broadband to a higher broadband:

If an employee is transferred or starts working in another function within his department, and the new function is classified in a higher broadband than the employee's current broadband, his salary will be increased by $5 \%$ as of the date of transfer or commencement of the new function with a minimum of $f$

${ }^{6}$ The equity theory can likewise be used to explain the existence of the fifth quartile. Employees that for historical reasons receive salaries exceeding the broadband maximum will receive substantially less salary increase, if at all.

${ }^{7}$ After having discussed these findings with the management of the company, it became apparent that the asymmetry in rewarding above and below average performance was not intended. Therefore it would make little sense to try to theoretically explain this intriguing characteristic of the compensation system. As a matter of fact, after having discussed these findings, the management decided to change the compensation system and eliminate the asymmetry. 
300.- (Euro 136.13) whereby the new salary must be at least equal to the

minimum salary of the new broadband.

The increase of $5 \%$ is similar to the result found by BGH (1994b) of 5.1\% - 7.4\%. In the next section we will investigate how the rules affect real-time wages.

\subsection{Personnel Data}

We have collected five years (1998-2002) of personnel data for all employees that have worked for the company over that period. The research site employed 632 persons in 2002 , which is also the survey year. Table 3 presents statistics of the total sample (and also of the returned questionnaires).

\section{$<<$ INSERT TABLE 3 HERE $>>$}

A smaller database of 376 employees was compiled from the complete personnel file. This smaller sample consisted of all those employees who had been officially evaluated between 2000 and 2002. We will start this subsection with a comparison of the actual data and the CLA. In the remainder, we will focus on promotions.

In the previous subsection we have introduced the existence of regulations concerning the maximums and minimums within each broadband. A plot of the actual data is displayed in Figure 2. The figure shows that the maximums are not strictly enforced. Especially in broadband 2 the salaries of some employees surpass the maximum. These salaries are frozen, but it is very unlikely that they will easily fall back into the broadband range.

$<<$ INSERT FIGURE 2 HERE $>>$ 
Table $4^{8}$ shows where the employees in our sample are located in the merit matrix. 24 employees receive a salary above the maximum permitted. Quartile four includes most employees: $31.6 \%$. The distribution along the vertical axis shows that none of the employees was rewarded an E-score for their performance over the year 2001. An A-score was almost equally rare: only 5 employees received such an assessment. A C-score was very commonly used; $70.7 \%$ of all employees received this evaluation score.

$<<$ INSERT TABLE 4 HERE $>>$

The combination of Table 3 and Table 4 draws us to conclude that incentive compensation is not heavily used: The merit matrix has only a limited monetary effect once a positive evaluation score is obtained. Moreover, there is little variation between the evaluation scores of the various employees. Therefore, we expect the motivating effect of the monetary reward system to be quite limited.

Another way to motivate employees is through promotions. In the year 2001, 42 employees received promotions, defined as an increase in broadband. In 2000 the number of employees with a promotion was $47 .^{9}$ As previously stated a promotion is accompanied with a salary increase of (at least) $5 \%$. Figure 3 displays the average salary increase attached to a promotion of the employees per broadband. Combining this figure with the merit matrix we see that the motivating effect of promotions is not limited to the salary increase in the first year. In addition, promotions transfer employees to a broadband where they will typically be placed in a lower quartile, where the multiplier, based on the merit matrix, is higher. Consequently the percentage salary increase for next year will be higher than the increase a employee would have received without the promotion, given a certain evaluation score. The

\footnotetext{
${ }^{8}$ The results of table 4 are based on 2001 data, but are consistent over time.

${ }^{9}$ A demotion is rare. In the period $1999-2002$ we find evidence of 32 demotions. This finding is consistent with $\mathrm{BGH}$. We will not discuss demotions in greater detail.
} 
maximum of the broadband to which the employee is promoted is also higher than the maximum of the old broadband. Thus, to summarize, (1) a promotion gives a salary increase of at least $5 \%,(2)$ the merit matrix will give a higher multiple conditional upon evaluation scores and (3) the spread towards the maximum of the broadband is greater.

\section{$<<$ INSERT FIGURE 3 HERE $>>$}

The earlier discussion of the CLA and the personnel data has concentrated on the various ways salary increases occur. The approach taken is similar to BGH (1994a), BGH (1994b), Lazear (1992), Lazear (1999) and Treble et al. (2001). But as has been shown, annual salary increases are the combined effect of different factors: the quartile position, the assessment score, and promotions. To gain a better understanding of these separate factors, in particular assessment scores and promotions, we analyze their individual determinants and pay attention to the potential interrelationships between the two. We shall then analyze the impact of the three factors (quartiles, assessment scores and promotions) on the annual salary increases over one's career. This extension will shed light on the incentive effect of promotions relative to the effects of assessment scores and fixed salary increases for employees until their retirement.

\section{Determinants of evaluation scores and promotion probability}

The data used to estimate the probability for employees to receive a specific assessment score was gathered for the sub sample of 376 employees. The variables we use are a combination of demographic variables (age and gender) and individual current (firm tenure, broadband, and quartile) and historical function information (assessments scores and promotions for the last two years). The variables "Age" and "Tenure" are continuous; whereas "Male" is a dummy variable equal to 1 for males and zero otherwise. The variables "Broadband" and "Quartile" 
describe the position of the employee within the firm and have an ordinal scale: "Broadband" ranges from 1 to 7 and "Quartile" from 1 to 5. The variable "Assessment score" is an ordinal variable as well that takes a value between 1 and 4,1 for an A-assessment score and 4 for a Dscore. The variable "Promotions" is a dummy variable, which is 1 if the employee went up in broadband in a certain year.

The suitable regression techniques for the two dependent variables, the assessment score and the dummy variable for promotion, are ordered probit and logit models. We conduct two regressions on the assessment scores: one, which includes promotions as an independent variable and one, which does not. The regression results are depicted in Table 5.

\section{$<<$ INSERT TABLE 5 HERE $>>$}

The results show that assessment scores are significantly related to historical performance; they are even linked to the assessment scores of two years ago. This finding is consistent with BGH's finding on serially correlated wage changes. Assessment scores are also related to promotions. On the one hand, assessment scores are significantly worse after an employee has received a promotion, consistent with Lazear's (2004) and other explanations of the Peter Principle. On the other hand, employees with a higher evaluation score are more likely to receive a promotion. Furthermore, we see that males are more likely to receive a promotion. The quartile of the employees has been indicated to have a positive relationship with the probability of a promotion. This implies that the company has a tendency to promote employees at the higher end of the salary range. The results also indicate that promotions are more unlikely for older employees and employees with a longer firm tenure. 


\section{Impact of quartile position, evaluation score, and promotion on wage development}

We use Monte Carlo Analysis to calculate the expected payout of each individual's career, in various contingencies, i.e. with(out) promotions and with(out) incentive compensation. We calculate the predicted probability for each assessment score and a promotion using the regression results of Table $5 .{ }^{10}$ Based on the rules in the CLA, we then calculate the expected salary level for each employee. The assessment scores and promotions the employees receive in one year are used as an input variable for next year's probability estimation and so on, until the employees reach retirement. The $\mathrm{N}$ factor in the merit matrix was set to the average $\mathrm{N}$ of the previous two years, $2.76 \%$.

We ran the model 200 times for four contingencies. The first is the situation in which every employee receives salary increases based on $\mathrm{C}$-assessment scores and promotions are excluded. The second condition includes the possibility of variation in assessment scores but does still not include promotion opportunities. The third condition includes promotions but excludes assessment scores whilst the fourth simulation includes both variables and therefore estimates the current situation within the firm. In each condition the end salary of the employees at the retirement age of 60 is calculated. The average annual salary increases derived for the four situations are depicted in Tables 6 and 7 and in Figure 4.

The first result shown in Table 6 is the very limited influence of the assessment scores on average compensation. The average salary increase until retirement will be $3.08 \%$ once we exclude promotions and assessments. Adding the impact of evaluation scores on the wage increase the comparable salary increase is $3.04 \%$ on average. A similar small effect of assessment scores is found given the occurrence of promotions $(3.45 \%$ salary increase in situation 3 versus $3.40 \%$ in situation 4$)$.

${ }^{10}$ To calculate the expected probability based on ordered probit results we use normal distributions and the calculated cut off points. To calculate the expected probability of promotions we use the logit results and applied the formula $\underset{p^{*}}{*}=\frac{1}{1+e^{\left(-y^{*}\right)}}$ to determine the partial effect. 
$<<$ INSERT TABLE 6 HERE $>>$

Figure 4 indicates the average salary increase for the four situations per quartile position. The average salary increase in the fourth quartile, once promotions and assessments are excluded, is $2.76 \%$ : the $\mathrm{N}$ of the matrix. The average salary increase for the same situation in the first quartile is $3.70 \%$. This is below the expected salary increase of $1.5 * 2.76$ $\%=4.14 \%$, since after some periods the employees automatically shift from the first quartile to the second quartile, and therefore their salary increase is reduced.

\section{$<<$ INSERT FIGURE 4 HERE $>>$}

The main aim of the Monte Carlo analysis was to identify the relative effect of promotions on lifetime compensation as compared to the other factors of influence, i.e. assessment scores and quartile positions. ${ }^{11}$ Table 7 displays the results per age group. The fraction of salary increases that depends on promotions is dependent on the age of the employees. For employees younger than 30 years old, the average salary increase will increase with $24.85 \%$ after introducing promotions. The importance of promotions diminishes over time; for older employees promotions are less likely and their impact on overall salary is therefore smaller.

$<<$ INSERT TABLE 7 HERE $>>$

\footnotetext{
${ }^{11}$ Note that the overall averages in Table 6 are the result of various effects, including the age of the employees.
} 
The conclusions of the combined discussion of the personnel data and the CLA are that we have found a limited incentive effect of evaluations. The two main reasons are the narrow variation in evaluation scores and the small impact of a positive evaluation score on compensation. Promotions, on the other hand, do have an important effect on overall compensation. Promotions enlarge the lifetime wage increases, which are largely depended on tenure, with roughly an additional $25 \% .{ }^{12}$ This is the sum of two effects, namely the immediate salary increase of at least $5 \%$ upon promotion and salary increases caused by the lower quartile position within the broadband subsequent to a promotion.

The detailed personnel data allow us to compare our results with those of the $\mathrm{BGH}$ papers (1994a, 1994b). When comparing their main conclusions to our results we find the following (BGH conclusions in italics): (1) Demotions are rare. We find similar results with a total of 32 demotions (1.6\%) over a four-year period. (2) Serial correlation in wage changes. We have found indirect support for this conclusion based on two grounds. First of all, evaluation scores are serially correlated. Second, the current quartile position of an employee is an important determinant of subsequent wage increases. (3) Wage increases precede promotions. This conclusion can also be supported by indirect evidence. High evaluation scores (not taken into account in the BGH papers) that lead to wage increases precede promotions. (4) Promotions are associated with large wage increases. The results show that promotions lead to a direct wage increase of $5 \%$. (5) The wage increase at a promotion is smaller than the difference in average wages. This conclusion is also supported (see figure 3 ). (6) Real wage cuts are not rare. Some employees that exceed the maximum receive no wage increase. Employees with a poor evaluation score receive very little wage increase. Therefore,

12 This is a conservative presentation of the importance of promotions to overall wage increase. One could argue that the $\mathrm{N}$-factor, representing the inflation, is the inflation correction for the wage. Calculating the real wage increase would lead to an expected average annual wage increase of $0.79 \%$ without promotions and $1.67 \%$ with promotions for employees beneath the 30 years old. This implies that promotions increase the expected wage increase by $111.91 \%$. 
we also find support for this conclusion. Due to the few years of personnel data available and the negative growth of the organization, we are unable to test the further BGH hypotheses, i.e. regarding a cohort effect and ports of entry/ exit. In sum, all six BGH conclusions are consistent with our findings. This similarity of results is remarkable given differences in decades, continents and industries. Building on our result so far, we will now investigate the incentive effect of promotions by combining the personnel files with a survey.

\subsection{Empirical Analysis of Motivation}

We have shown that promotions significantly affect salary levels and we therefore expect to find a positive effect on motivation. We have obtained the data on motivation of individual employees through a questionnaire. The questionnaire was also used to obtain other employee-specific information not available from the personnel data, such as education and expectations regarding promotions. The response rate was $28.3 \%$ (179 out of 632 employees returned a completed questionnaire, see Table 3). Three levels of education are distinguished, ranging from mid-school to university. Intrinsic and extrinsic motivation were measured by constructs consisting of 16 statements $^{13}$, see Table 8 . Factor analysis confirmed the common wisdom in psychology that a two-factor solution is plausible. The rotated factor solutions are depicted in Table 8. Cronbach's alpha for the combination of the nine statements regarding intrinsic motivation is .75. The alpha score for extrinsic motivation was .73 .

$$
<<\text { INSERT TABLE } 8 \text { HERE }>>
$$

\section{Promotions in A Timeframe}

\footnotetext{
13 The constructs are similar to the statements used in van Herpen, van Praag and Cools (2002). In order to measure extrinsic motivation we included statements regarding motivational aspects of the compensation system, performance measurement and promotions. Reliability analysis and factor analysis both confirmed the believe that all these elements should be included.
} 
The date of the last promotion as well as the moment at which the next promotion occurs are expected to have an impact on the level of motivation. Both economic and motivational theories expect to find a positive relationship between extrinsic motivation and the prospect of a promotion. Motivational theories also imply a positive relationship between the prospect of a promotion and intrinsic motivation, due to a higher level of self-determination. Motivational theory furthermore implies a negative relationship between the amount of time since the last promotion and intrinsic motivation. If employees have been doing the same job for a very long time, it would seem logical that the job encompasses fewer challenges and thereby lowers the level of immediate need satisfaction and consequently decreases the level of intrinsic motivation.

To test the hypothesized relationship between expected and realized promotions on the one hand and intrinsic and extrinsic motivation on the other, we run regressions in which the constructs intrinsic and extrinsic motivation (measured by both the average of the component statements and by the factor results) are the dependent variables. The independent variables are the time of the realized and expected promotions and control variables. Four dummy variables describe the timing of realized promotions: The first three dummy variables are 1 if a promotion has occurred at $t-1, t-2$ and $t-3$ respectively. If no promotion has occurred, the fourth dummy is equal to one (this dummy variable is excluded from the regression). Another set of four dummy variables describes the timing of the next expected promotion, based on the employees' perception, i.e.: the next promotion is expected within one year, within 3 years, within 5 years or after more than five years. The reference category is "no promotion expected". Table 9 shows the result of the regressions. In order to test the robustness of the results we conducted the analyses by using both the average results as well as the factor results as independent variables. We also included intrinsic and extrinsic motivation as independent variables in order to control for spill over effects. 
First, the results show that extrinsic motivation is mainly affected by the expectancy of a future promotion. If an employee expects a promotion to be near, i.e. within one to three years, his or her extrinsic motivation increases. The result holds for both the average score and the factor result. ${ }^{14}$ Second, intrinsic motivation is affected by both realized and expected promotions. A past promotion has an increasing effect on intrinsic motivation. This effect is significant in the second and third year after a promotion, not the first. It appears that it takes employees one to two years to get used and become knowledgeable and somewhat experienced in their new job/ position before they get full satisfaction from their work. Also the expectancy of a future promotion increases intrinsic motivation. The effects of control variables are also notable. We find the persistent result that older employees and employees in the higher broadbands have a higher level of intrinsic and extrinsic.

Figure 5 presents the results graphically. The scores for extrinsic and intrinsic motivation are displayed for the four dummies of historical promotions and for the four dummies on the expectancy of promotions. Figure 5a presents the standardized average scores and figure $5 \mathrm{~b}$ the factor scores. The graphs show that intrinsic motivation as a function of historical and prospective promotions can best be characterized by two inverted U's. The forward-looking inverted $U$ is much more damped than the backward-looking. It appears that intrinsic motivation is highest in the middle period between two promotions (two to three years after a previous promotion, with the expectation of getting another promotion within two years). The graph for extrinsic motivation shows a different shape. The expectation of a promotion has a positive effect on extrinsic motivation and this effect diminishes over time.

\footnotetext{
${ }^{14}$ One could argue that the statements regarding promotions that measure extrinsic motivation drives our results. Excluding either of these two statements does not affect the results: the expectancy of a future promotion within the next 1 year or the 2 year following is consistently positively related to extrinsic motivation.
} 
For extrinsic motivation the backward-looking effect is much more damped than the forwardlooking graph. Therefore, the overall conclusion is that intrinsic motivation is most heavily affected by historical promotions, whereas extrinsic motivation is affected by future promotions.

\section{$<<$ INSERT FIGURE 5 HERE $>>$}

\section{Conclusions}

In this article we empirically analyze wage structures and the incentive effects of promotions within one company. We compare our findings to the results by $\mathrm{BGH}$, focusing on the determinants of promotions, the effect of a promotion on remuneration, and the effect of both realized and expected promotions on intrinsic and extrinsic motivation. The empirical tests are based on personnel files in combination with individually linked survey results on employees' perceptions of promotion possibilities and motivation.

Our first investigations of this Anglo/Dutch company have mainly focused upon the CLA the company uses. We report that wages are attached to jobs and not so much to employees, in line with the human capital theory. Furthermore, the immediate wage increase upon promotion is $5 \%$.

Besides the fact that wages are attached to jobs, we find that the company uses a convex wage structure and that promotions contribute very significantly to lifetime income: roughly $25 \%$ of lifetime wage changes are a direct or indirect result of promotions. The impact on total rewards of incentive compensation based on subjective evaluation scores is very limited both due to its design (small effect of evaluation score on wages) and due to its use and implementation (evaluation scores are fairly uniform). 
We have also investigated the incentive effect of promotions. Models have described the promotions to be job-assignment mechanisms (e.g. Waldman, 1984, Gibbons and Waldman, 1999b), an incentive instrument (e.g. Lazear and Rosen, 1981). This paper has demonstrated that promotions have an incentive effect in line with the expectancies of the tournament model. Indeed, the prospect of a promotion increases the level of extrinsic motivation. A realized promotion, however, only modestly affects extrinsic motivation, but heavily affects intrinsic motivation. We find an inverted U-shaped relationship between the amount of time passed between promotions and intrinsic motivation. On the contrary, extrinsic motivation increases with the expectation of a promotion but falls back after the promotion has occurred, especially if the last promotion took place a long time in the past.

Besides theoretical implications, studies on internal labor markets can also have great managerial impact. The incentive effect of rewards can be used to steer on effort through either incentive compensation or promotion premiums. Previously papers have shown that incentive compensation is related to extrinsic motivation (e.g. van Herpen, van Praag and Cools, 2003). This study shows that an expected promotion will increase not only extrinsic motivation, but also intrinsic motivation. Two years after a promotion the employees will have a high level of intrinsic motivation, which diminishes over time. Incentive compensation can be seen as an alternative for promotions, as far as promotions are related to extrinsic motivation. The significant relationship between promotion and intrinsic motivation cannot be mimicked by incentive compensation. Our findings indicate the strong motivating potential of promotions, both intrinsically and extrinsically.

The limitations to this study are mainly related to problems arising from the data source used. The research site is a single company and the results might therefore not generally hold (although our findings are strikingly consistent withy BGH). Especially our conclusions regarding the lifetime wage increase do not include the possibility of leaving the company to work elsewhere and the accompanying impact on the wage level. However, the 
company did provide us with the possibility to investigate the issues in a single cultural setting and with a single compensation system being used. These control factors are extremely important for the precise measurement of effects. A second limitation is that the expectation of a promotion is measured subjectively only. The data gave us little room to create an inflow and outflow model that would be able to derive the expectancies of a promotion objectively. On the other hand, motivation is caused by the perceived expectations of a promotion, irrespective whether this expectation is correct.

Overall, the research site provides unique data on three different levels: the labor agreement, the personnel files, and the motivational survey amongst employees. Analyzing these data sources in combination enabled us to study some predictions from tournament theory and to validate an important assumption of the model: promotions provide incentives. 


\section{REFERENCES}

Baker, G.P., M. Gibbs and B. Holmstrom (1994a), "The Internal Economics of The Firm: Evidence From Personnel Data," Quarterly Journal of Economics, 109: 881-919

----. (1994b), “The Wage Policy of A Firm,” Quarterly Journal of Economics, 109: 921-955

Becker, G.S. (1962), "Investment in Human Capital: A Theoretical Analysis," The Journal of Political Economy, 70: 9-49

Bénabou, R. and J. Tirole (2003), "Intrinsic and Extrinsic Motivation”, Review of Economic Studies, 70: 489-520

Bernhardt, D. and D. Scoones (1993), "Promotion, Turnover and Preemptive wage offers," American Economic Review, 84: 771-91

Bingley, P. and T. Eriksson (2001), "Pay Spread and Skewness, Employee Effort and Firm Productivity," Working Paper

Carmichael, L. (1983), "Firm-specific human capital and promotion ladders," Bell Journal of Economics, 14: 251-58

Coupé, T., V. Smeets and F. Warzynski (2004), “Incentives in Economic Departments: Testing Tournaments?" Working Paper

Deci, E.L. (1975), Intrinsic Motivation, New York and London: Plenum Press

Deci, E.L. and R.M. Ryan (1985), Intrinsic Motivation and Self-Determination in Human Behavior, New York and London: Plenum Press

Doeringer, P. and M. Piore (1971), Internal Labor Markets and Manpower Analysis, Heath Lexington Books, Lexington, MA

Dohmen, T.J., B. Kriechel and G.A. Pfann (2003), "Monkey Bars and Ladders: The Importance of Lateral and Vertical Job Mobility in Internal Labor Market Careers," Journal of Population Economics, Forthcoming 
Ehrenberg, R.G. and M.L. Bognanno (1990a), "The Incentive Effects of Tournaments Revisited: Evidence from the European PGA Tour," Industrial and Labor Relations Review, 43: 74-88

----. (1990b), “Do Tournaments Have Incentive Effects?” Journal of Political Economy, 98: $1307-1324$

Eriksson, T. (1999), "Executive Compensation and Tournament Theory: Empirical Tests on Danish Data," Journal of Labor Economics, 17: 262-280

Frey, B.S. (1997a), Not just for the money. An economic theory of personal motivation, Cheltenham (UK): Edward Elgar publishing ltd.

----. (1997b), “On the Relationship Between Intrinsic and Extrinsic Work Motivation”, International Journal of Industrial Organization, 4: 427-439

Gibbons, R. (1997), “Incentives and Careers in Organizations,” in D. Kreps and K. Wallis (eds.), Advances in Economic Theory and Econometrics, Vol. 2, New York: Cambridge University press

Gibbons, R. and M. Waldman (1999a), "Careers in Organizations: Theory and Evidence," in O. Ashenfelter and D. Card (eds.) Handbook of Labor Economics, Vol. 3., Amsterdam: North Holland

----. (1999b), “A Theory of Wage and Promotion Dynamics Inside Firms,” Quarterly Journal of Economics, 114: 1321-1358

Jovanovic, B. (1979), “Job Matching and the Theory of Turnover," Journal of Political Economy, 87: 972:90

Knoeber, C.R. and W.N. Thurman (1994), "Testing the Theory of Tournaments: An Empirical Analysis of Broiler Production,” Journal of Labor Economics, 12: 155-179

Kreps, D.M. (1997), “Intrinsic Motivation and Extrinsic Incentives,” American Economic Review, 87: 359-364 
Kunz, A.H. and D. Pfaff (2002), “Agency theory, performance evaluation, and the hypothetical construct of intrinsic motivation", Accounting, Organization and Society, 27: $275-295$

Lawler, E.E. (1986), “The Design of Effective Reward System,” in Lorsch, J. ed., Handbook of Organizational Behavior, Englewood Cliffs (NJ): Prentice-Hall

Lazear, E.P. (1992), "The Job as a Concept," in W. Bruns. (eds.), Performance Measurement, Evaluations, and Incentives, Boston: Harvard Business School Press

----. (1995), Personnel Economics, Cambridge (MA): MIT Press

----. (1999), “Personnel Economics: Past Lessons and Future Directions," Journal of Labor Economics, 17: 199-236

----. (2000), "Performance, Pay and Productivity", American Economic Review, 50: 13461361

----. (2004), “The Peter Principle: A Theory of Decline,” Journal of Political Economy, 112, no. S1

Lazear, E.P. and S. Rosen (1981), "Rank-Order Tournaments as Optimum Labor Contracts", Journal of Political Economy, 89: 841-864

Lima, F. and P.T. Pereira (2003), "Careers and Wages within Large Firms: Evidence from a Matched Employer-Employee Data Set," International Journal of Manpower, 24: 812835

Locke, E.A. and D. Henne (1986), “Work motivation theories, ” in C.L. Cooper and I. Robertson (eds.), International review of industrial and organizational psychology, 135, Chichester (UK): Wiley

Main, B., C. O’Reilly and J. Wade (1993), “Top Executive Pay: Tournaments of Teamwork," Journal of Labor Economics 11: 606-28 
Medoff, J. and K. Abraham (1980), “Experience, Performance and Earnings,” Quarterly Journal of Economics, 95: 703-736

O’Reilly, C., B. Main and G. Crystal (1988), “CEO Compensation as Tournament and Social Comparison: A Tale of Two Theories," Administrative Science Quarterly, 33: 257-74

Rosen, S. (1986), "Prices and Incentives in Elimination Tournaments," American Economic Review, 76: 701-715

Sattinger, M. (1993), “Assignment models of the distribution of earnings,” Journal of economic literature, 31: 831-80

Treble, J., E. van Gameren, S. Bridges and T. Barmby (2001), “The Internal Economics of the Firm: Further Evidence from Personnel Data," Labour Economics, 8: 531-620

Taylor, B.A. and J.G. Trogdon (2002), "Losing to Win: Tournaments Incentives in the National Basketball Association,” Journal of Labor Economics, 20: 23-41

Van Herpen, M.F.M., C.M. van Praag and K. Cools (2003), “The Effects of Performance Measurement and Compensation on Motivation; an Empirical Study," Working Paper

Waldman, M. (1984), “Job Assignment, Signaling and Efficiency,” Rand Journal of Economics, 15: 255-267 
Figure 1

Broadbanding in the Collective Labor Agreement

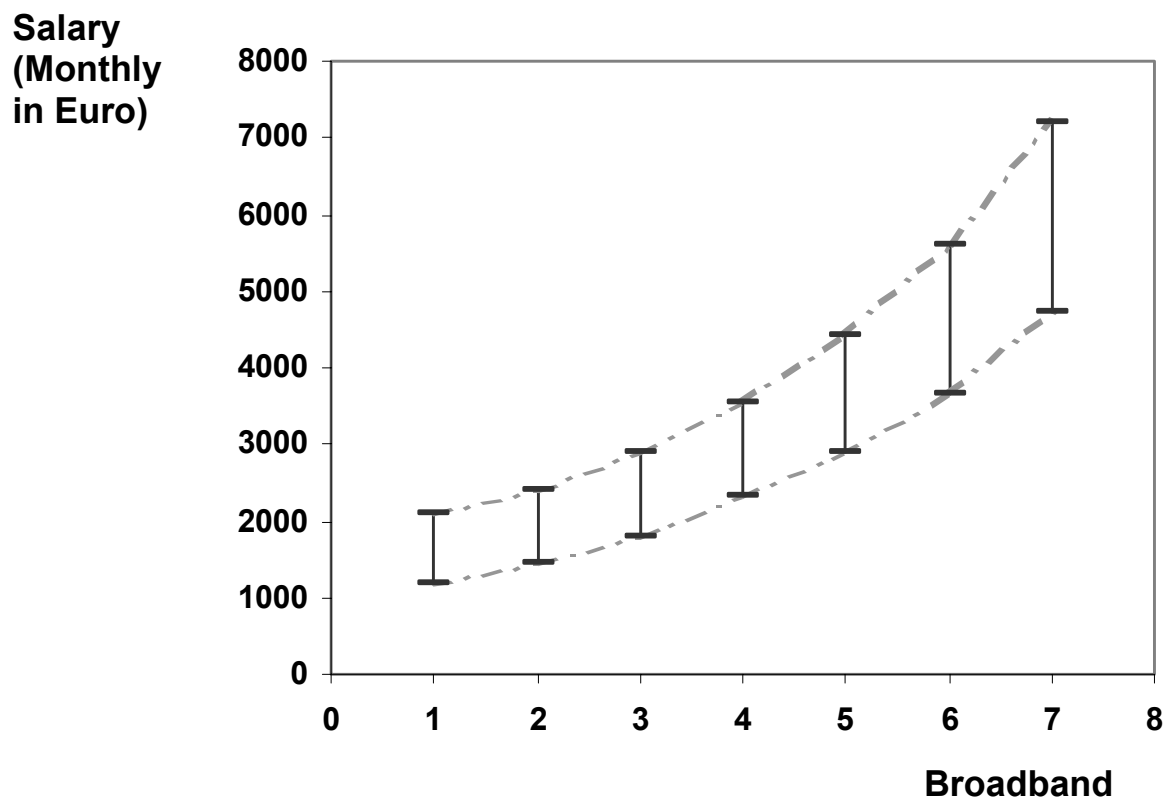

Figure 2

Employees' position in the broadband

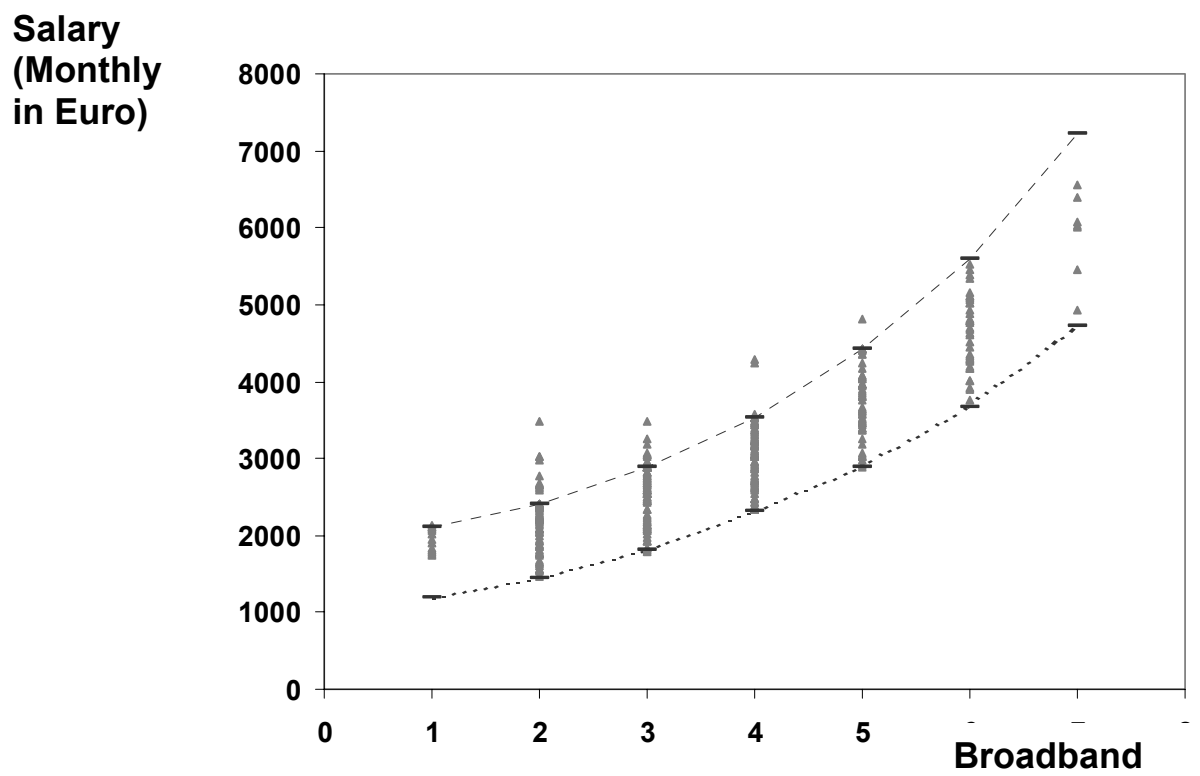


Figure 3

Average promotion between broadbands

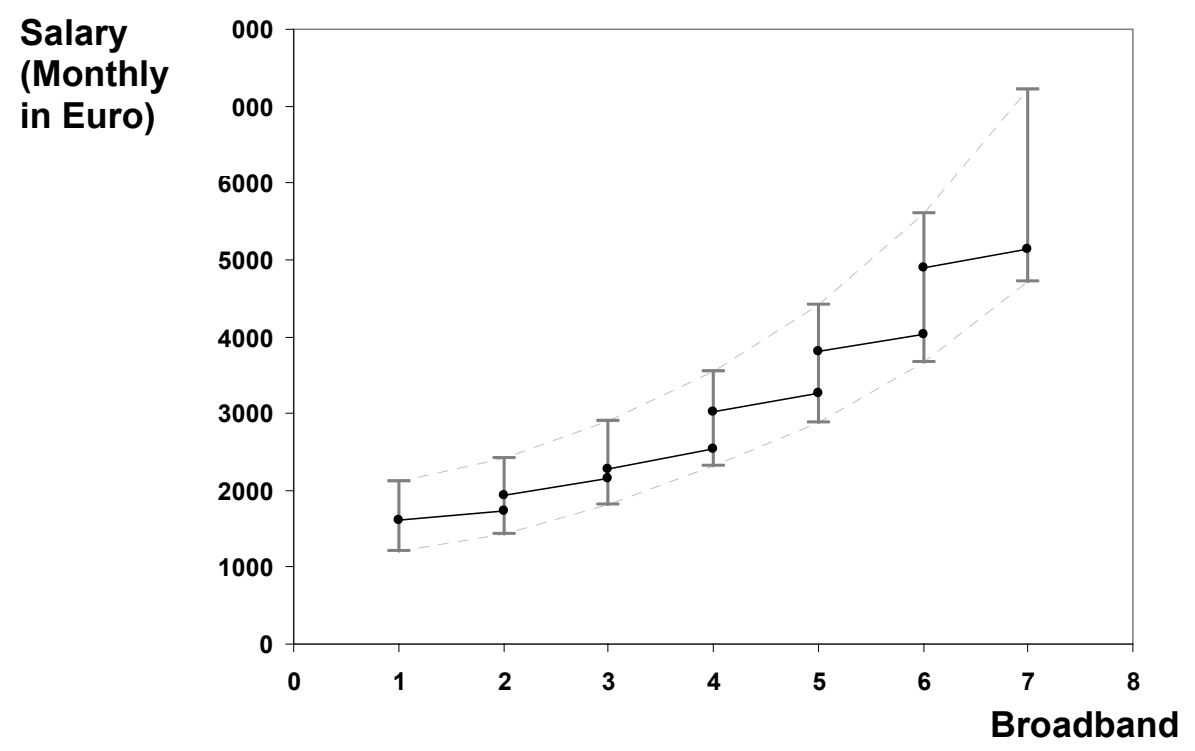

Figure 4

Average salary increase per quartile

Average annual salary increase

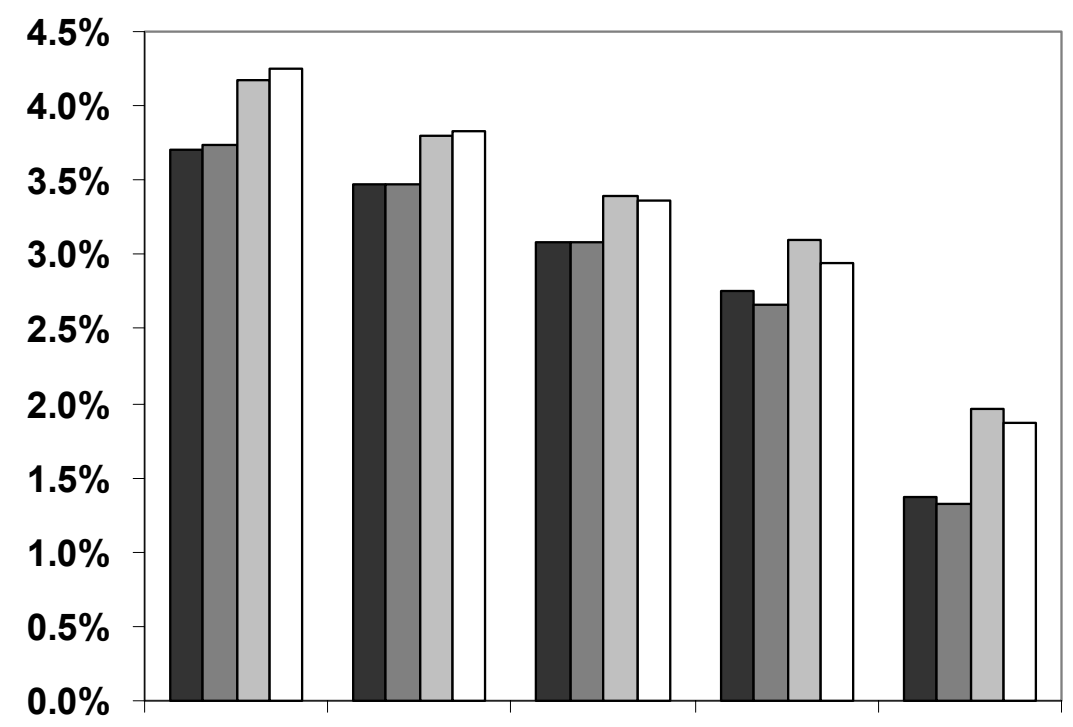

$\square$ No promotions/ no evaluations

$\square$ No promotions/ with evaluations

$\square$ With promotions/ no evaluations

$\square$ With promotions/ with evaluations

Quartile 1 Quartile 2 Quartile 3 Quartile 4 Quartile 5

(frozen) 
Figure 5A

Standardized average scores of motivation

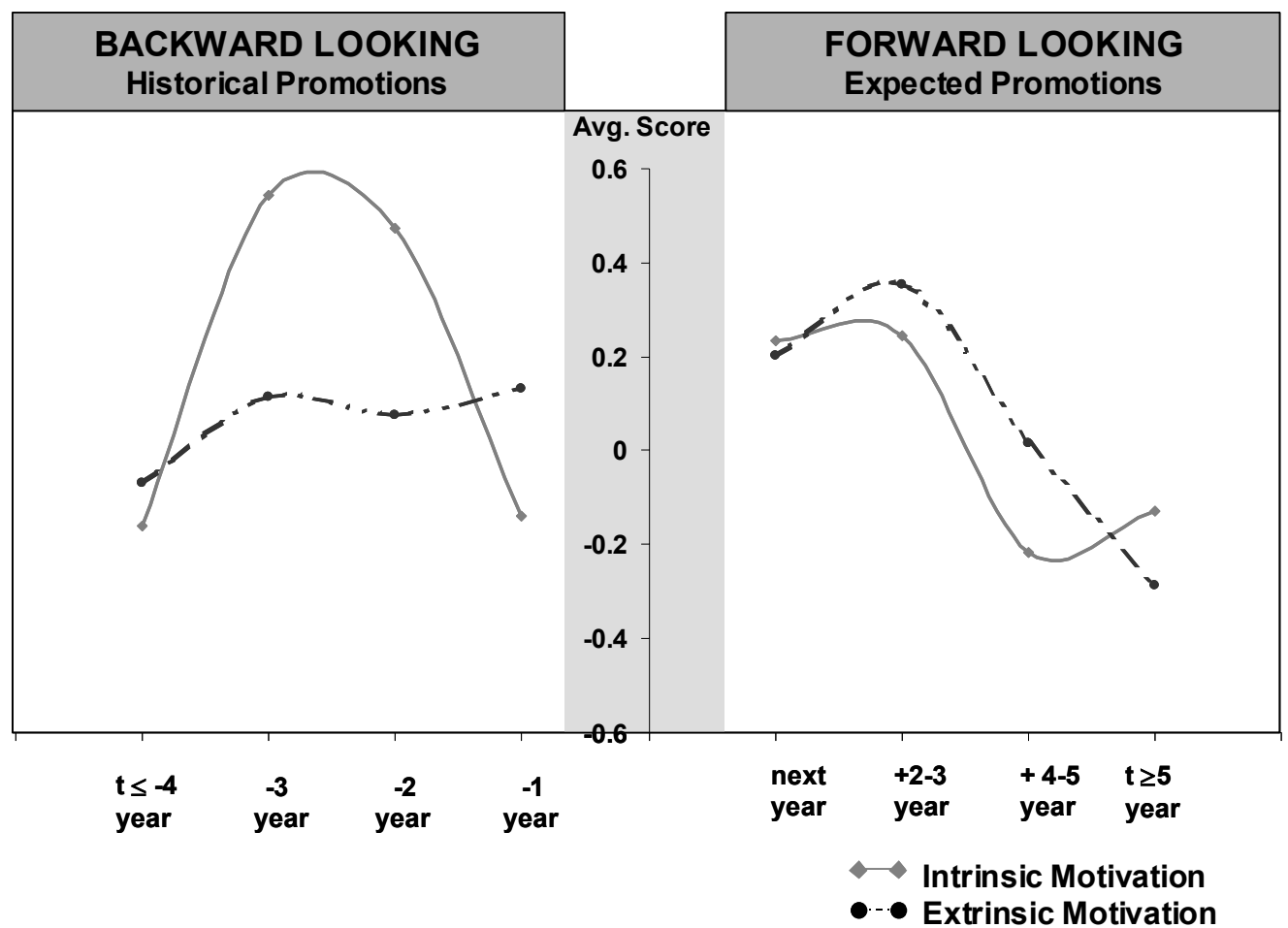

Figure 5B

Factor results for motivation

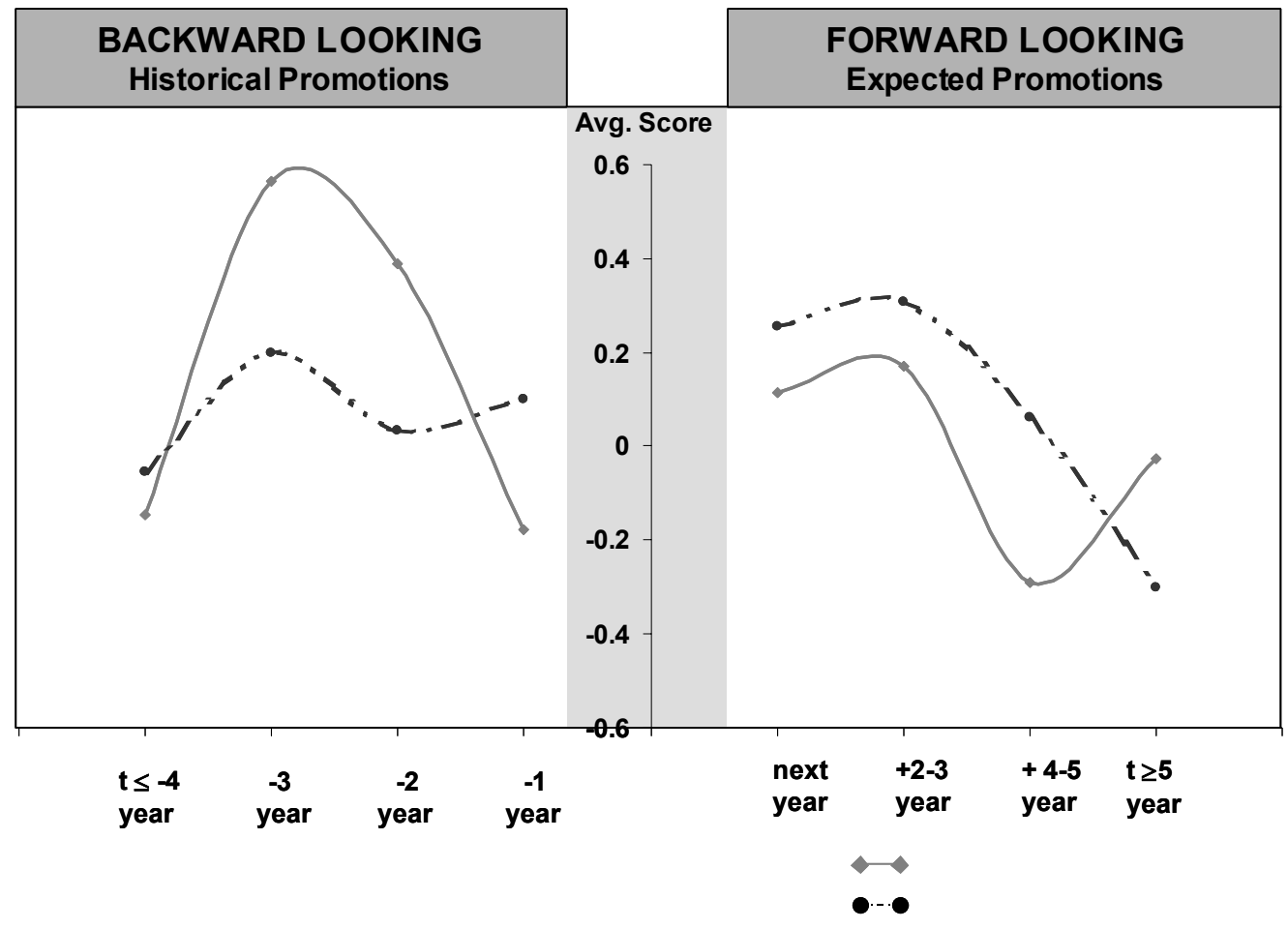


Table 1

Salary increase between broadband maximums and minimums

\begin{tabular}{lcccccc}
\hline & $\mathbf{1 \rightarrow 2}$ & $\mathbf{2} \rightarrow \mathbf{3}$ & $\mathbf{3 \rightarrow 4}$ & $\mathbf{4 \rightarrow \mathbf { 5 }}$ & $\mathbf{5 \rightarrow \mathbf { 6 }}$ & $\mathbf{6 \rightarrow 7}$ \\
\hline Minimum & $19.6 \%$ & $26.0 \%$ & $28.3 \%$ & $24.7 \%$ & $26.8 \%$ & $28.9 \%$ \\
Maximum & $14.4 \%$ & $20.2 \%$ & $22.2 \%$ & $24.7 \%$ & $26.8 \%$ & $28.9 \%$ \\
\hline
\end{tabular}

\section{Table 2}

Merit Matrix

\begin{tabular}{|c|c|c|c|c|c|c|}
\hline & & \multicolumn{5}{|c|}{ Quartile } \\
\hline & & 1 & 2 & 3 & 4 & 5 \\
\hline Evaluation & $\mathbf{A}$ & $2 * N$ & $1.75 * \mathrm{~N}$ & $1.5 * \mathrm{~N}$ & $1.35 * \mathrm{~N}$ & $0.8 * \mathrm{~N}$ \\
\hline score & B & $1.75 * \mathrm{~N}$ & $1.5 * \mathrm{~N}$ & $1.35 * \mathrm{~N}$ & $1.2 * \mathrm{~N}$ & $0.4 * N$ \\
\hline & $\mathbf{C}$ & $1.5 * \mathrm{~N}$ & $1.35 * \mathrm{~N}$ & $1.2 * \mathrm{~N}$ & $1 * N$ & $0 * \mathrm{~N}$ \\
\hline & D & $0.8 * \mathrm{~N}$ & $0.6 * \mathrm{~N}$ & $0.4 * \mathrm{~N}$ & $0.2 * \mathrm{~N}$ & $0 * \mathrm{~N}$ \\
\hline & $\mathbf{E}$ & $0 * \mathrm{~N}$ & $0 * \mathrm{~N}$ & $0 * \mathrm{~N}$ & $0 * \mathrm{~N}$ & $0 * \mathrm{~N}$ \\
\hline
\end{tabular}


Table 3

Descriptive statistics

\begin{tabular}{|c|c|c|c|c|c|}
\hline & & \multicolumn{2}{|c|}{ Total Sample } & \multicolumn{2}{|c|}{ Questionnaire } \\
\hline & & $\mathrm{N}$ & percentage & $\mathrm{N}$ & percentage \\
\hline \multirow[t]{6}{*}{ Age } & Age $<25$ & 25 & $4.0 \%$ & 9 & $5.0 \%$ \\
\hline & Age $25-35$ & 151 & $23.9 \%$ & 56 & $31.3 \%$ \\
\hline & Age $35-45$ & 206 & $32.6 \%$ & 53 & $29.6 \%$ \\
\hline & Age $45-55$ & 165 & $26.1 \%$ & 39 & $21.8 \%$ \\
\hline & Age $>55$ & 85 & $13.4 \%$ & 10 & $5.6 \%$ \\
\hline & Unknown & 0 & $0.0 \%$ & 12 & $6.7 \%$ \\
\hline \multirow[t]{6}{*}{ Tenure } & Tenure $<3$ & 125 & $19.8 \%$ & 34 & $19.0 \%$ \\
\hline & Tenure $3-5$ & 202 & $32.0 \%$ & 62 & $34.6 \%$ \\
\hline & Tenure $5-10$ & 61 & $9.7 \%$ & 22 & $12.3 \%$ \\
\hline & Tenure $10-15$ & 41 & $6.5 \%$ & 7 & $3.9 \%$ \\
\hline & Tenure $>15$ & 199 & $31.5 \%$ & 41 & $22.9 \%$ \\
\hline & Unknown & 4 & $0.6 \%$ & 13 & $7.3 \%$ \\
\hline \multirow[t]{3}{*}{ Gender } & Male & 452 & $71.5 \%$ & 128 & $71.5 \%$ \\
\hline & Female & 180 & $28.5 \%$ & 51 & $28.5 \%$ \\
\hline & Unknown & 0 & $0.0 \%$ & 0 & $0.0 \%$ \\
\hline \multirow[t]{8}{*}{ Broadband } & Broadband 1 & 22 & $3.5 \%$ & 5 & $2.8 \%$ \\
\hline & Broadband 2 & 139 & $22.0 \%$ & 21 & $11.7 \%$ \\
\hline & Broadband 3 & 114 & $18.0 \%$ & 37 & $20.7 \%$ \\
\hline & Broadband 4 & 116 & $18.4 \%$ & 34 & $19.0 \%$ \\
\hline & Broadband 5 & 86 & $13.6 \%$ & 31 & $17.3 \%$ \\
\hline & Broadband 6 & 68 & $10.8 \%$ & 23 & $12.8 \%$ \\
\hline & Broadband 7 & 25 & $4.0 \%$ & 7 & $3.9 \%$ \\
\hline & Unknown & 62 & $9.8 \%$ & 21 & $11.7 \%$ \\
\hline \multirow[t]{4}{*}{ Level } & Head Office & 224 & $35.4 \%$ & 78 & $43.6 \%$ \\
\hline & Region Europe & 167 & $26.4 \%$ & 42 & $23.5 \%$ \\
\hline & Area Central & 237 & $37.5 \%$ & 47 & $26.3 \%$ \\
\hline & Unknown & 4 & $0.6 \%$ & 12 & $6.7 \%$ \\
\hline \multirow[t]{7}{*}{ Job Family } & Financial & 103 & $16.3 \%$ & 31 & $17.3 \%$ \\
\hline & Staff & 79 & $12.5 \%$ & 34 & $19.0 \%$ \\
\hline & Sales/Marketing & 88 & $13.9 \%$ & 20 & $11.2 \%$ \\
\hline & Transport & 153 & $24.2 \%$ & 54 & $30.2 \%$ \\
\hline & Customer & & & & \\
\hline & Services & 147 & $23.3 \%$ & 24 & $13.4 \%$ \\
\hline & Unknown/ other & 62 & $9.8 \%$ & 16 & $8.9 \%$ \\
\hline Total & & 632 & & 179 & \\
\hline
\end{tabular}


Table 4

Number of observations in the merit matrix

\begin{tabular}{lccccccc}
\hline & & $\mathbf{1}$ & $\mathbf{2}$ & $\mathbf{3}$ & $\mathbf{4}$ & $\mathbf{5}$ & Quartile \\
\hline Evaluation & A & 2 & 2 & 1 & & & 5 \\
score & B & 17 & 20 & 28 & 20 & 5 & 90 \\
& C & 46 & 46 & 65 & 92 & 17 & 266 \\
& D & 2 & 2 & 2 & 7 & 2 & 15 \\
& E & 0 & 0 & 0 & 0 & 0 & 0 \\
\hline & Total & 67 & 70 & 96 & 119 & 24 & 376 \\
\hline
\end{tabular}

Table 5

Regression results: prediction of assessment scores and promotions

\begin{tabular}{|c|c|c|c|c|c|c|}
\hline \multirow{2}{*}{$\begin{array}{l}\text { Indep. Var. } \\
\text { Assessment } \mathrm{t}-1\end{array}$} & \multicolumn{2}{|c|}{$\begin{array}{c}\text { (1) } \\
\text { Assessment } t=0\end{array}$} & \multicolumn{2}{|c|}{$\begin{array}{c}(2) \\
\text { Assessment } t=0\end{array}$} & \multicolumn{2}{|c|}{$\begin{array}{c}\text { (3) } \\
\text { Promotion }\end{array}$} \\
\hline & $\begin{array}{r}0.74 \\
(0.15)\end{array}$ & $* * *$ & $\begin{array}{r}0.71 \\
(0.14)\end{array}$ & $* * *$ & $\begin{array}{r}-0.40 \\
(0.38)\end{array}$ & \\
\hline Assessment $\mathrm{t}-2$ & $\begin{array}{r}0.44 \\
(0.16)\end{array}$ & $* * *$ & $\begin{array}{r}0.38 \\
(0.15)\end{array}$ & $* *$ & $\begin{array}{r}-0.69 \\
(0.4)\end{array}$ & $*$ \\
\hline Promotion $\mathrm{t}=0$ & $\begin{array}{r}0.40 \\
(0.22)\end{array}$ & $*$ & & & & \\
\hline Promotion $\mathrm{t}-1$ & $\begin{array}{r}0.55 \\
(0.22)\end{array}$ & $* *$ & & & $\begin{array}{l}-0.83 \\
(0.66)\end{array}$ & \\
\hline Promotion $\mathrm{t}-2$ & & & & & $\begin{array}{r}0.38 \\
(0.55)\end{array}$ & \\
\hline Age & $\begin{array}{r}0.01 \\
(0.01)\end{array}$ & & $\begin{array}{r}0.01 \\
(0.01)\end{array}$ & & $\begin{array}{l}-0.10 \\
(0.03)\end{array}$ & $* * *$ \\
\hline Broadband & $\begin{array}{l}-0.05 \\
(0.06)\end{array}$ & & $\begin{array}{r}-0.07 \\
(0.06)\end{array}$ & & $\begin{array}{l}-0.53 \\
(0.19)\end{array}$ & $* * *$ \\
\hline Male & $\begin{array}{r}-0.13 \\
(0.17)\end{array}$ & & $\begin{array}{r}0.00 \\
(0.16)\end{array}$ & & $\begin{array}{r}1.00 \\
(0.45)\end{array}$ & $* *$ \\
\hline Quartile & $\begin{array}{r}0.10 \\
(0.07)\end{array}$ & & $\begin{array}{r}0.07 \\
(0.07)\end{array}$ & & $\begin{array}{r}0.57 \\
(0.23)\end{array}$ & $* *$ \\
\hline Tenure & $\begin{array}{r}0.01 \\
(0.01)\end{array}$ & $*$ & $\begin{array}{r}0.01 \\
(0.01)\end{array}$ & & $\begin{array}{r}-0.05 \\
(0.02)\end{array}$ & $* *$ \\
\hline Constant & & & & & $\begin{array}{r}4.85 \\
(1.70)\end{array}$ & $* * *$ \\
\hline $\begin{array}{l}\text { Cut_off } 1 \\
\text { Cut_off } 2 \\
\text { Cut_off } 3\end{array}$ & $\begin{array}{l}1.56 \\
3.44 \\
6.16\end{array}$ & & $\begin{array}{l}0.92 \\
2.75 \\
5.42\end{array}$ & & & \\
\hline $\begin{array}{l}\mathrm{N} \\
\text { Chi squared } \\
\text { Pseudo R squared }\end{array}$ & $\begin{array}{r}376 \\
69.38 \\
0.119\end{array}$ & & $\begin{array}{r}376 \\
60.21 \\
0.104\end{array}$ & & $\begin{array}{r}376 \\
55.03 \\
0.209\end{array}$ & \\
\hline
\end{tabular}

Note: Standard errors are in parentheses

* Statistically significant at the .10 level; ** at the .05 level; *** at the .01 level (two tailed tests) 


\section{Table 6}

\section{Descriptive statistics of Monte Carlo results}

\begin{tabular}{llccccc}
\hline & & Minimum & Median & Average & Maximum & St. dev. \\
\hline (1) & $\begin{array}{l}\text { No promotions } \\
\text { No evaluations }\end{array}$ & $0.00 \%$ & $3.10 \%$ & $3.08 \%$ & $4.14 \%$ & 0.0060 \\
(2) & $\begin{array}{l}\text { No promotions } \\
\text { With evaluations }\end{array}$ & $0.00 \%$ & $3.10 \%$ & $3.05 \%$ & $4.83 \%$ & 0.0066 \\
(3) & $\begin{array}{l}\text { With promotions } \\
\text { No evaluations } \\
\text { (4) }\end{array}$ & $0.00 \%$ & $3.45 \%$ & $3.44 \%$ & $8.19 \%$ & 0.0077 \\
& $\begin{array}{l}\text { With promotions } \\
\text { With evaluations }\end{array}$ & $0.00 \%$ & $3.42 \%$ & $3.40 \%$ & $8.91 \%$ & 0.0089 \\
\hline
\end{tabular}

Table 7

Monte Carlo results organized by age groups

\begin{tabular}{llcccc}
\hline & & \multicolumn{3}{c}{ Age } & \\
& & $<30$ & $30-40$ & $40-50$ & $50-60$ \\
\hline (1) & $\begin{array}{l}\text { No promotions } \\
\text { No evaluations }\end{array}$ & $3.56 \%$ & $3.37 \%$ & $3.03 \%$ & $2.75 \%$ \\
(2) & $\begin{array}{l}\text { No promotions } \\
\text { With evaluations }\end{array}$ & $3.55 \%$ & $3.38 \%$ & $3.00 \%$ & $2.70 \%$ \\
(3) & $\begin{array}{l}\text { With promotions } \\
\text { No evaluations }\end{array}$ & $4.36 \%$ & $3.89 \%$ & $3.37 \%$ & $2.90 \%$ \\
(4) & $\begin{array}{l}\text { With promotions } \\
\text { With evaluations }\end{array}$ & $4.43 \%$ & $3.95 \%$ & $3.33 \%$ & $2.74 \%$ \\
& & & & \\
& $2 \leftrightarrow 4$ & $24.85 \%$ & $16.80 \%$ & $10.97 \%$ & $1.55 \%$ \\
\hline
\end{tabular}

Table 8

Factor loadings of the constructs extrinsic and intrinsic motivation

\begin{tabular}{lrr}
\hline & $\begin{array}{c}\text { Component 1: } \\
\text { Extrinsic } \\
\text { Motivation }\end{array}$ & $\begin{array}{c}\text { Component 2: } \\
\text { Intrinsic } \\
\text { Motivation }\end{array}$ \\
\hline The manner in which I am compensated ensures that I am motivated & 0.612 & 0.055 \\
to give the fullest effort possible. & 0.657 & -0.200 \\
I'm satisfied with the way in which my compensation is determined. & & \\
I get the feeling that the company finds it important to have a solid & 0.580 & 0.097 \\
and clear compensation system. & 0.719 & 0.047 \\
I find the compensation system to be motivating. & 0.538 & -0.003 \\
The agreed targets motivate me to exert effort. & 0.472 & 0.067 \\
I have full control over my ability to get promoted. & & \\
There are enough promotion possibilities that stimulate me to work & 0.597 & 0.163 \\
hard. & & \\
If it's really necessary I'm prepare to work overtime even if I don't & 0.075 & 0.456 \\
get paid for this specifically. & 0.381 & 0.650 \\
I get a lot of satisfaction out of the work I do. & -0.103 & -0.762 \\
I often have to force myself to got to work. & 0.388 & 0.662 \\
Usually I'm enthusiastic about my job. & -0.109 & -0.627 \\
While at work I often feel like the day will never end. & -0.320 & 0.566 \\
I think I understood my work pretty well. & -0.232 & 0.456 \\
I'm good at my work, compared to other colleagues. & 0.313 & 0.666 \\
My job makes all my effort worthwhile. & 0.121 & -0.287 \\
I feel tense while working. & & \\
\hline
\end{tabular}


Table 9

Regression results: promotions in a time-frame

\begin{tabular}{|c|c|c|c|c|c|c|c|c|c|c|}
\hline \multirow[b]{3}{*}{ Hist. Promotion $\mathrm{t}-1$} & \multicolumn{7}{|c|}{ Averages } & \multicolumn{3}{|c|}{ Factor Results } \\
\hline & \multicolumn{3}{|c|}{$\begin{array}{l}\text { Extrinsic } \\
\text { motivation }\end{array}$} & \multicolumn{4}{|c|}{$\begin{array}{l}\text { Intrinsic } \\
\text { motivation }\end{array}$} & $\begin{array}{c}\text { Extrinsic } \\
\text { motivation }\end{array}$ & \multicolumn{2}{|l|}{$\begin{array}{l}\text { Intrinsic } \\
\text { motivation }\end{array}$} \\
\hline & $0.22(0.15)$ & & $0.19(0.15)$ & $0.14(0.11)$ & & $0.12(0.11)$ & & $0.36(0.26)$ & $0.22(0.26)$ & \\
\hline Hist. Promotion $\mathrm{t}$ - 2 & $0.18(0.15)$ & & $0.12(0.16)$ & $0.29(0.11)$ & $* *$ & $0.27(0.11)$ & $* *$ & $0.28(0.28)$ & $0.51(0.28) *$ & * \\
\hline Hist. Promotion $\mathrm{t}-3$ & $0.25(0.18)$ & & $0.17(0.19)$ & $0.39(0.13)$ & $* * *$ & $0.36(0.13)$ & $* * *$ & $0.53(0.33)$ & $0.86(0.33) *$ & $* *$ \\
\hline Exp. Promotion $<1$ year & $0.35(0.16)$ & $* *$ & $0.30(0.16) *$ & $0.23(0.11)$ & $* *$ & $0.19(0.12)$ & & $0.65(0.29) * *$ & $0.34(0.28)$ & \\
\hline Exp. Promotion 2-3 years & $0.27(0.14)$ & $* *$ & $0.22(0.14)$ & $0.24(0.10)$ & $* *$ & $0.21(0.10)$ & $* *$ & $0.47(0.25) *$ & $0.53(0.25) *$ & $* *$ \\
\hline Exp. Promotion $4-5$ years & $-0.01(0.21)$ & & $-0.01(0.20)$ & $-0.03(0.15)$ & & $-0.02(0.15)$ & & $0.11(0.37)$ & $-0.03(0.37)$ & \\
\hline Age & $0.01(0.01)$ & & $0.01(0.01)$ & $0.01(0.01)$ & $* *$ & $0.01(0.01)$ & $* *$ & $0.02(0.01) *$ & $0.03(0.01) *$ & $* *$ \\
\hline Broadband & $0.06(0.04)$ & & $0.05(0.04)$ & $0.08(0.03)$ & $* * *$ & $0.08(0.03)$ & $* *$ & $0.11(0.08)$ & $0.14(0.07) *$ & $*$ \\
\hline Male & $-0.17(0.12)$ & & $-0.17(0.12)$ & $-0.02(0.09)$ & & $0.00(0.09)$ & & $-0.42(0.23) *$ & $0.05(0.22)$ & \\
\hline Tenure (log) & $-0.25(0.16)$ & & $-0.25(0.16)$ & $-0.01(0.12)$ & & $0.02(0.12)$ & & $-0.47(0.29)$ & $0.07(0.29)$ & \\
\hline Education low & $0.24(0.13)$ & $*$ & $0.23(0.13) *$ & $0.05(0.10)$ & & $0.03(0.10)$ & & $0.35(0.25)$ & $-0.04(0.24)$ & \\
\hline Education middle & $0.04(0.13)$ & & $0.06(0.13)$ & $-0.12(0.09)$ & & $-0.12(0.09)$ & & $0.11(0.24)$ & $-0.36(0.23)$ & \\
\hline Assessment $\mathrm{t}$ - 1 & $0.16(0.10)$ & & $0.17(0.10)$ & $-0.03(0.08)$ & & $-0.05(0.08)$ & & $0.25(0.19)$ & $-0.18(0.19)$ & \\
\hline Intrinsic Motivation (avg) & & & $0.20(0.13)$ & & & & & & & \\
\hline Extrinsic Motivation (avg) & & & & & & $0.11(0.07)$ & & & & \\
\hline Constant & $1.55(0.41)$ & $* * *$ & $0.99(0.55) *$ & $2.78(0.30)$ & $* * *$ & $2.62(0.31)$ & $* * *$ & $-2.12(0.75) * * *$ & $-1.6(0.74) *$ & $* *$ \\
\hline $\mathrm{N}$ & 118 & & 118 & 118 & & 118 & & 118 & 118 & \\
\hline R-squared & 0.238 & & 0.255 & 0.327 & & 0.341 & & 0.212 & 0.254 & \\
\hline Adj R-squared & 0.144 & & 0.154 & 0.244 & & 0.253 & & 0.115 & 0.162 & \\
\hline
\end{tabular}

Note: Standard errors are in parentheses

* Statistically significant at the .10 level; ** at the .05 level; *** at the .01 level (two tailed tests) 